\title{
Plants vs. Streams: Their groundwater-mediated competition at "El Morro", a developing catchment in the dry plains of Argentina
}

\author{
Esteban Jobbágy ${ }^{1}$, Santiago Lorenzo ${ }^{2}$, Ricardo Páez ${ }^{1}$, Nicolás Buono ${ }^{3}$, Yésica Díaz ${ }^{1}$, \\ Victoria Marchesini ${ }^{1}$, and Marcelo Nosetto ${ }^{4}$ \\ ${ }^{1}$ Instituto de Matematica Aplicada San Luis \\ ${ }^{2}$ Instituto Nacional de Tecnología Agropecuaria \\ ${ }^{3}$ Universidad Nacional de la Plata \\ ${ }^{4}$ Instituto de Matemática Aplicada San Luis
}

October 9, 2020

\begin{abstract}
Our understanding of the mechanisms routing precipitation inputs to evapotranspiration and streamflow in catchments is still very fragmented, particularly in the case of saturated flows. Here we explore five mechanisms by which plants and streams compete with each other for water, based on multiple scales of observations in a flat semiarid sedimentary catchment of central Argentina subject to abrupt hydrological transformations. Since the 80s, the "El Morro" catchment $\left(1334 \mathrm{~km} 2,-33.64^{\circ},-65.36^{\circ}\right)$ experienced a fast expansion of crops over native forests and grasslands, rapid water table level rises ( $\sim 0.3 \mathrm{~m}$ y-1), spontaneous expansion of wetlands and permanent streams by groundwater sapping. Based on episodic and continuous groundwater level, stream flow, and remote sensing data we show that plants not only take away water from streams by drying the unsaturated zone (mechanism 1), but by tapping the saturated zone in the expanding waterlogged environments (mechanism 2) and in the upland environments that remain uncultivated and display increasing tree cover (mechanism 3). Conversely, streams take away water from plants through pulsed bed-deepening and water table depression (mechanism 4), and riparian and wetland zones burying with fresh sediments (mechanism 5). While earlier work established widespread support for mechanisms 1 preventing stream formation, diurnal and seasonal fluctuations of water table levels and base streamflow records in this study proved the importance of mechanisms 2 and 3 under the current high-water table conditions. These data together with remotely-sensed greenness showed a growing but localized relevance of mechanism 4 and 5 as the stream network developed. The distinction of recharge- vs. topography-controlled groundwater systems is useful to organize the interplay of these concurrent mechanisms. Findings point to the unsaturated-saturated contact zone as a crucial and dynamic hub for water partition and for ecological, geomorphological, and hydrological knowledge integration.
\end{abstract}

\section{Hosted file}

jobbagy et al - HP catchments - MS 3.pdf available at https://authorea.com/users/12925/ articles/485792-plants-vs-streams-their-groundwater-mediated-competition-at-el-morro-adeveloping-catchment-in-the-dry-plains-of-argentina

\section{Hosted file}

Table 1 - BASE FLOW AND YIELD SYNTHESIS.xlsx available at https://authorea.com/users/12925/ articles/485792-plants-vs-streams-their-groundwater-mediated-competition-at-el-morro-adeveloping-catchment-in-the-dry-plains-of-argentina

\section{Hosted file}


Table 2 - MODIS NDVI.xlsx available at https://authorea.com/users/12925/articles/485792plants-vs-streams-their-groundwater-mediated-competition-at-el-morro-a-developingcatchment-in-the-dry-plains-of-argentina
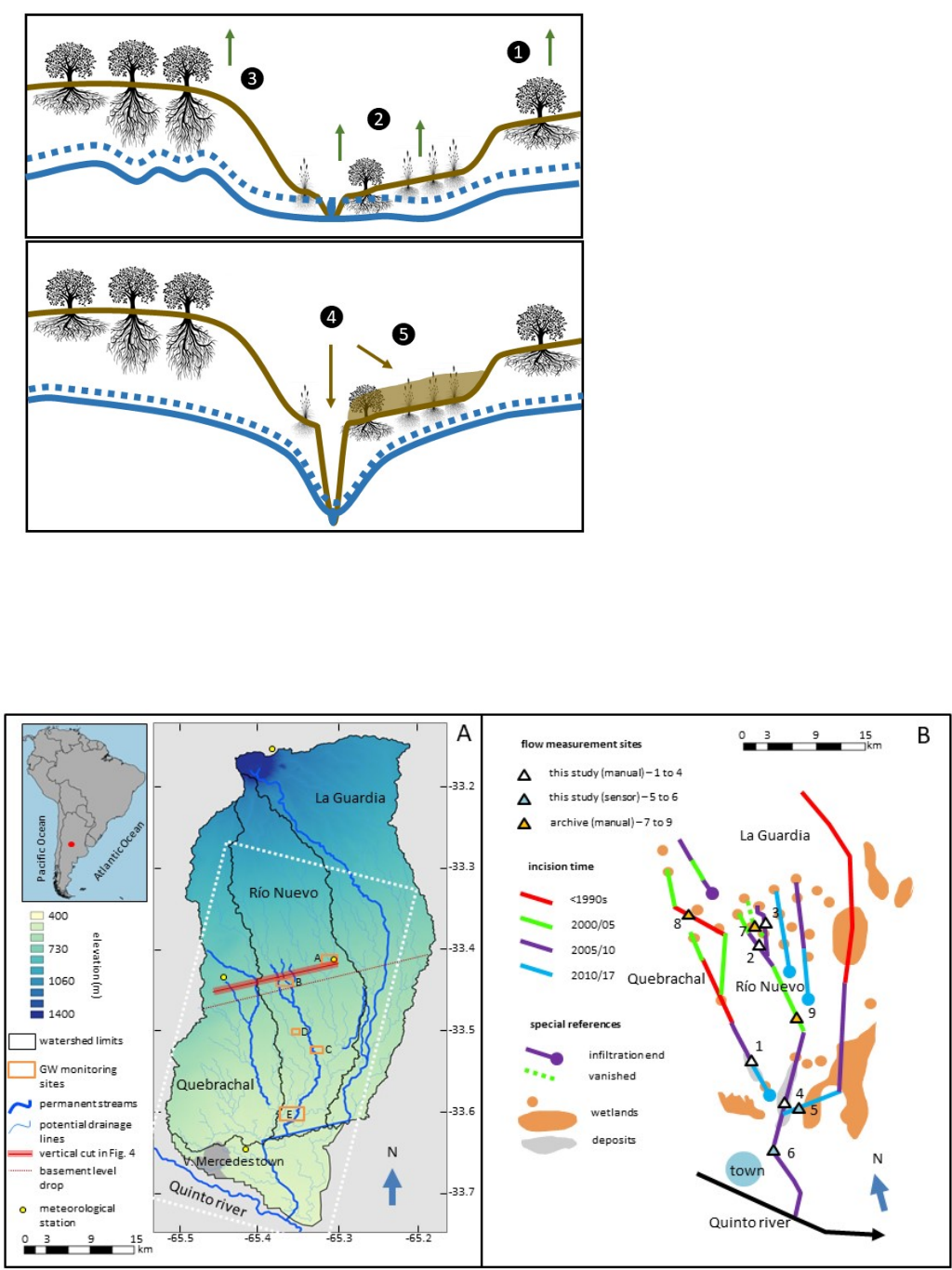

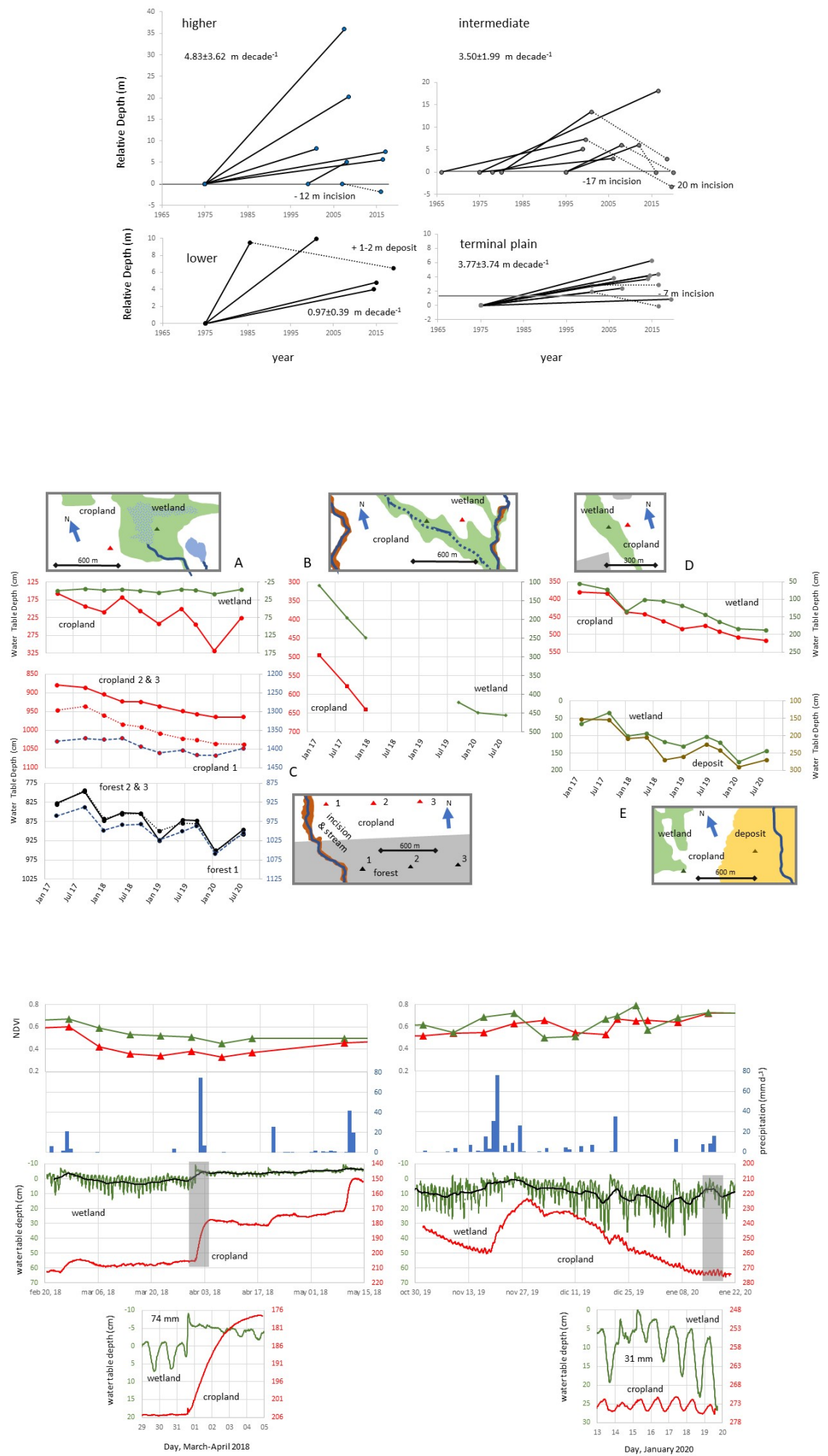

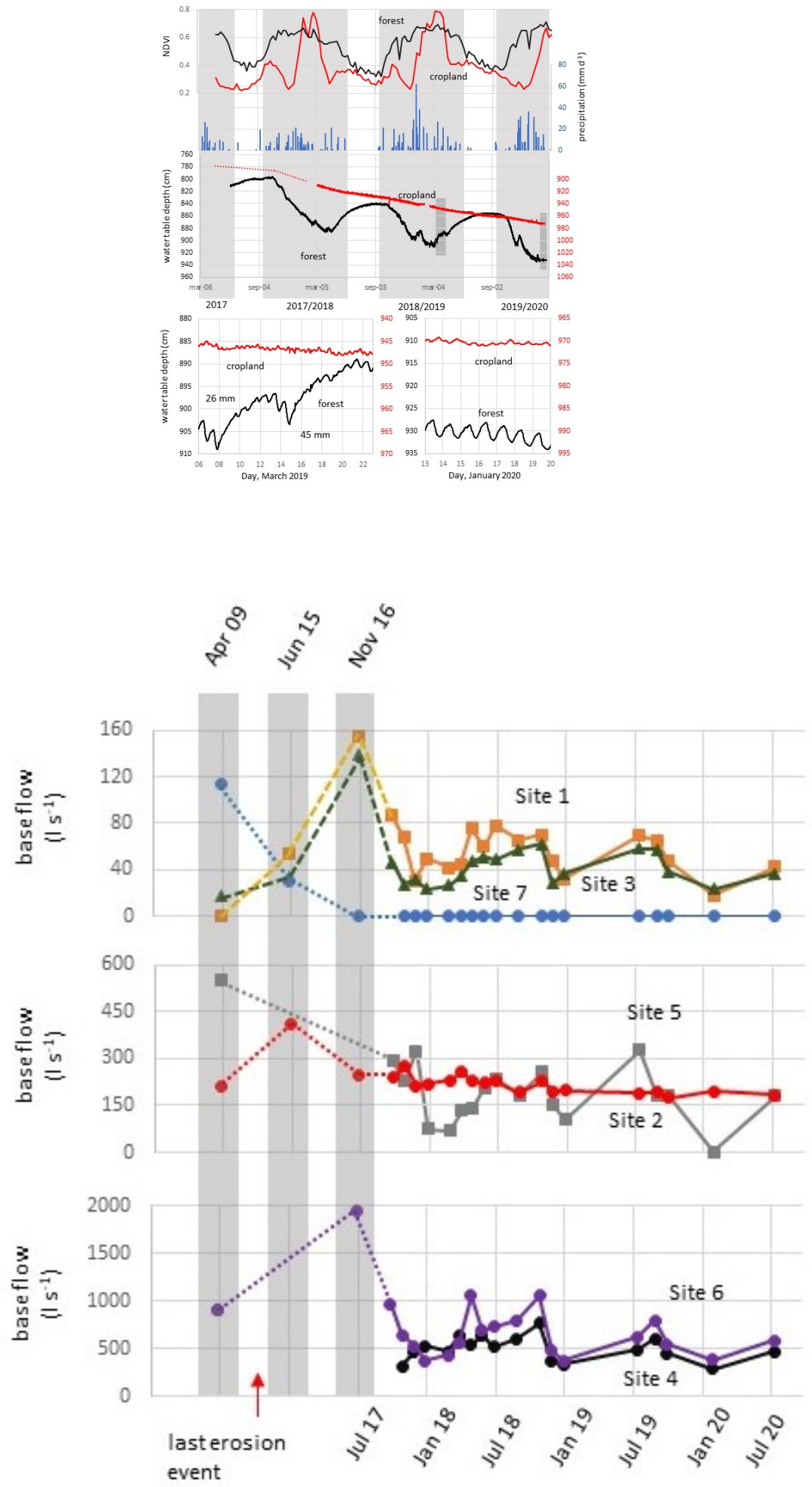


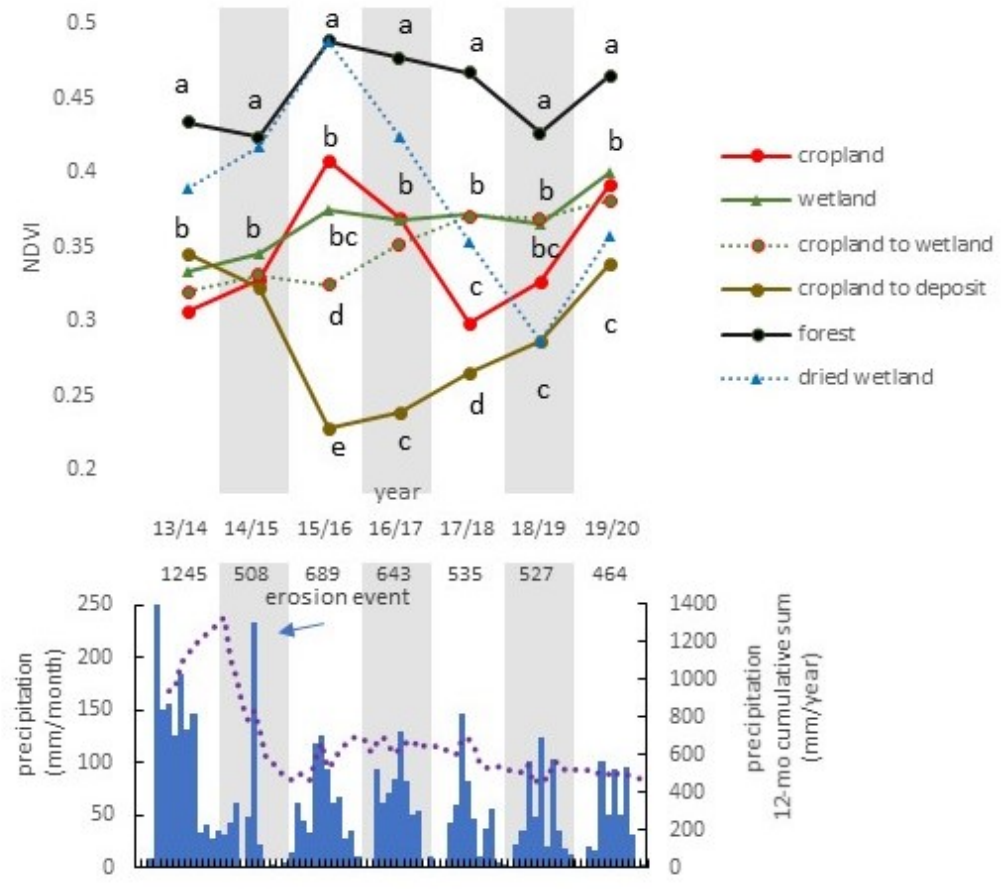

